\title{
THE ECONOMIC IMPLICATIONS OF PREVENTIVE HEALTH CARE*
}

\author{
KENNETH E. WARNer \\ Dept. of Health Planning \& Administration. School of Public Health. University of Michigan. \\ Ann Arbor. Michigan 48109, U.S.A.
}

\begin{abstract}
Today's cost-conscious political environment subjects the economic implications of proposed health care expenditures to careful scrutiny. This paper examines both the logic of and the evidence on preventive health care activities' ability to serve the objective of health cost containment. Following a brief introduction to benefit-cost analysis, the paper presents a prevention activity classification schema intended to clarify distinctions among the modalities of prevention and to differentiate activities with significant cost-containment potential from those which seem to offer less potential. Empirical evidence supports the conventional wisdom that primary prevention activities are frequently cost-effective. particularly when the recipient's role is relatively passive (e.g. receiving an immunization) and when the prevention measure is a public good delivered to an entire community (e.g. water fluoridation). The existing success of such traditional public health measures suggests that future prevention opportunities may lie in nontraditional activities which violate "rules" of effective health care delivery or communication of prevention information. For example, the broadcast media may prove to be a cost-effective vehicle for health cducation. despitc the impersonal character of the media and the required "activation" of the viewer/listener.

Whatever prevention's long-run cost-containment potential might be, the near-term outlook for support of prevention activities is clouded by the budgetary myopia of the political system. the lack of a vocal constituency for prevention. and a limited base of solid understanding of the health and economic consequences of numerous prevention measures
\end{abstract}

\section{INTRODUCTION}

An economist's paraphrasing of the public health folk wisdom might read. "A dollar of prevention is worth $\$ 16$ of cure". Particularly in today's cost-conscious political environment. the economic implications of any proposal for health care expenditure are subject to careful scrutiny. For this reason, many advocates of prevention efforts promote their cause by appealing to its economic logic: prevention, they assert, saves health care dollars. Skeptics respond that preventive activities necessarily incur costs in the short run, and with long-run effects often unestablished, the costcontainment case for prevention is weak. Naturally. the nature of existing empirical evidence is such that each side can illustrate its case with rather vivid examples.

The cost of health care is certainly today's most politically sensitive health issue. The decade of the 1980 s will open with annual U.S. expenditures on health care exceeding $\$ 200$ billion. or $\$ 900$ per man,

* An earlier version of this paper was presented at the 106th Annual Meeting of the American Public Health Association. Los Angeles. Cal. October 1978. The paper is based on work performed for the Citizens Research Council of Michigan. I am grateful for the support of the Council. but wish to emphasize that opinions expressed in the paper are solely my own. I am also grateful to Lawrence Stiffman and an anonymous referee for helpful comments on an earlier draft of the paper. My understanding of the dimensions of prevention has benefited from discussions with O. Lynn Deniston and Myron Wegman. Needless to say. I alone bear responsibility for any remaining errors or deficiencies.

+ This is the Cooper and Rice [1] estimate of 1972 productivity losses inflated to current prices. woman, and child. At least as disturbing as the magnitude of expenditures is their rate of growth. Current expenditures are more than 15 times what they were in 1950, implying an annual growth rate of $10 \%$ during a period in which general consumer prices rose less than half as rapidly. The problem is particularly acute at the governmental level. Government's share of expenditures remained fairly stable at $20-25 \%$ from 1950 through the mid-1960s. Since 1965, however. public spending has incrcased twice as rapidly as that of the private sector. Consequently, the public sector now accounts for close to $45^{\circ}$ of all health care expenditures.

The true costs of illness are not adequately measured by health care expenditure data. for they do not include indirect costs - the lost productivity due to morbidity, disability, and premature mortality, and the pain and suffering which illness inflicts. No one has succeeded in placing an cconomically meaningful value on the latter. However, the other indirect costs - the productivity losses-can be valued at another $\$ 190$ billion. + Thus illncss costs this nation close to $\$ 400$ billion per year.

The magnitude and rate of growth of health care expenditures have placed a high priority on attempts to contain costs. To date. efforts have emphasized containing the direct costs of an established pattern of medical services, principally by discouraging "unnecessary" or marginally less useful services. The centerpiece of the current effort is the containment of hospital costs, the most visible and institutional source of medical cost inflation. Federal legislation has been introduced by the Carter Administation, and the hospital industry has responded with its own program of "voluntary" cost containment. 
The idea of attempting to contain health care costs through prevention is, like prevention itself. something of a step-child. The argument that investing today in an apparently healthy person can save resources tomorrow is theoretically appealing. but it suffers from uncertainties about its actual payoffs. reactions to its overzealous promotion. and perhaps the myopia with which we define our social. as well as individual, approaches to caring for health. Nevertheless. federal resources devoted to prevention are increasing rapidly, though their absolute magnitude remains quite small. In an era of cost-consciousness and restrictions on new discretionary spending, this growth can be interpreted as indicating at least some receptivity to the idea of prevention-qua-cost-containment.

The purpose of this paper is to examine whether or not prevention activities might serve to contain the growth in health care costs. The remaining pages explore what we know, what we need to know, and how such knowledge might usefully be applied both publicly and privately.* Before discussing empirical knowledge. I will present a simple conceptual structure for assessing whether or not an individual preventive activity "pays its own way". In economic jargon, this is benefit-cost methodology, familiar in name to virtually everyone, if not always in substance. Following that presentation (which may be skipped by anyone with a basic understanding of benefit-cost analysis). I develop a prevention activity classification schema to clarify distinctions among the modalities of prevention. The classification schema also differentiates activities which seem likely to be cost-saving from those whose cost-containment potential appears limited. Ultimately, each activity must be evaluated individually, irrespective of its position within this schema. But I will argue that certain types or classes of activities with considerable potential have been neglected in policy circles, while others may have been oversold.

\section{FRAMING THE QUESTION: THE METHODOLOGY OF BENEFIT-COST ANALYSIS}

The basic question addressed in this paper is conceptually simple: how do the current costs of a preventive activity compare with later health costs avoided due to the activity's preventing or postponing illness? The question becomes complex when attempt-

* It should be emphasized that the potential of prevention is examined from only one perspective: its ability to limit health care expenditures by avoiding or postponing illness and premature mortality. Thus important nonpecuniary benefits related to enhancement of the quality of life are ignored. A complete assessment of the value of preventive care would most certainly weigh all pecuniary and nonpecuniary. direct and indirect benefits and costs

† As noted above, a theoretically complete analysis would include assessment of nonpecuniary benefits such as reduction in pain and suffering or enhancement of quality of life. Though often ignored altogether or mentioned and then left out of formal analysis, such benefits have occasionally been incorporated into quantitative analyses [2]. Acton [3] uses a "willingness-to-pay" approach to valuing benefits which implicitly places a value on pain and suffering a voided. ing to make the requisite measurements. Two "production functions" must be determined. First. we must define the process of producing the preventive activity: what are the inputs (types of personnel. capital equipment. supplies) which go into "making" a unit of the activity and how are these inputs combined (in what proportions and numbersi? Second. and more difficult, we must estimate the outputs or outcomes of the activity, over time. by amount of the activity, and by population groups experiencing the activity. Once these production functions are defined. they must be "costed out": by pricing inputs we can estimate the costs of producing the activity. and $b$ y pricing the later health care and productivity losses avoided or postponed. we can estimate the benefitsthe costs averted-to be derived from the activity. Once the costs and benefits are appropriately discounted (a procedure noted below). comparison of benefits and costs permits assessment of the activity's cost-containment potential. +

Determining production relationships and then valuing inputs and outcomes in monetary terms are obviously very difficult tasks. The inability to perform these tasks with precision does not necessarily invalidate the analysis, though it is a principal reason that many analyses are summarily dismissed as being of no utility. A simple procedure exists to ascertain whether or not the conclusion of an analysis is significantly affected by uncertainties, subjective assumptions and the like. Called sensitivity analysis, this procedure involves repeating the benefit and cost calculations for high, low. and best estimates of the value of an uncertain variable. For example. if one estimates the benefits of a screening program at $\$ 10$ million. but feels there may be an error margin of $\pm 25^{\circ} \%$ the comparison of benefits and costs should be repeated for benefit estimates of $\$ 12.5$ million and $\$ 7.5$ million. in addition to the best estimate of $\$ 10$ million. If the screening program has a cost of $\$ 5$ million. uncertainty about the true value of the benefits is shown to be of no consequence: even with the low estimate of $\$ 7.5$ million in benefits, the program still produces at net benefit of $\$ 2.5$ million. The "break-even" level of benefit--that level below which the program would be economically unattractive-is $\$ 5$ million. a full $50^{\circ}$; below the best estimate. Thus, inability to assess benefits precisely does not interfere with ability to examine the economic worthiness of the screening program. Conversely, the analysis would be sensitive to the estimate if programmatic costs totaled $\$ 9$ million. In this situation the best estimate of benefit- $\$ 10$ million-makes the program look attractive inet benefit equals $\$ 1$ million), but with the low estimate- $\$ 7.5$ million-the program shows a net loss of $\$ 1.5$ million. Consequently. the analysis is sensitive to the estimation of benefit. and a prudent analyst for legislator) would not find the analysis an adequate basis for a policy recommendation.

A final issue to be addressed in this cursorv introduction to benefit-cost methodology is how one deals with the fact that benefits and costs do not accrue all at once and rarely follow similar patterns of accrual over time. A one-time hypertension screening program will have its major costs occurring within a single period. However. the benefits of the program--anvoidance of health costs and lost produc- 
Health Measure

\begin{tabular}{|l|l|l|l|l|}
\hline Delivered \\
by
\end{tabular}

Fig. 1. A classification of prevention activities

tivity due to detection and treatment of high blood pressures-would be realized over a period of many years. Especially if the screened population is predominantly young. significant benefits might not begin to accrue until several years following the screening. The importance of this is that, even ignoring inflation, a dollar today is valued more highly than a dollar tomorrow.* An analyst needs to make current and future dollars commensurate to determine the present value of the streams of benefits and costs. This is achieved by discounting (or diminishing) all benefits and costs which occur in the future. When significant benefits or costs accrue in the future. the process of discounting can radically affect one's perception of net benefit; that is, discounted net benefit may differ dramatically from undiscounted net benefit. Furthermore, the ranking of program alternatives can be very sensitive to both the process of discounting and the specific value of the discount rate. Program A may have a greater net benefit than program $B$ when benefits and costs are discounted at $5 \%$, but program B's net benefit may exceed program A's when a discount rate of $10^{\circ}$ is used.

For many people, both the concept and methodo logy of discounting are confusing. The purpose of the preceding paragraph is simply to alert the reader to the economic significance of the fact that future benefits and costs must be deflated to be compared with present benefits and costs. A general feature of benefit-cost analysis, discounting is particularly important in the case of preventive activities since so many of

* To convince yourself of this. consider your response to the following. If I offered to hand you a $\$ 100$ bill today or to give you $\$ 100$ (in real terms, i.c.. adding whatever was necessary to cover inflation) 20 years from now. which would you take? Few people respond "20 years from now." The implication is that the vast majority "discount" the value of money over time.

+ Several technical discussions of the theory and mathematics of discounting are available elsewhere [4.5]. Baumol [6] presents an excellent treatment of determination of the appropriate social discount rate. The literature contains numerous useful discussions of benefit-cost analysis and its close relative. cost-effectiveness analysis. as they apply to health $[7-11]$. the benefits occur well into the future. In addition, discounting helps to explain how postponing illness costs can have the effect of containing them. This phenomenon-an important feature of some prevention efforts-is illustrated in the concluding section of this paper.t

\section{PREVENTIVE HEALTH CARE ACTIVITIES: A ClASSIFICATION}

The tendency to subsume a variety of activities under the single label, prevention, obscures important distinctions among them. Figure 1 presents a classification schema which identifies some of these distinctions and thereby facilitates investigation of the question of whether or not specific preventive activities can contain health care costs. The content of cells in the schema is indicated by examples. Crucial distinctions across cells are discussed in the following paragraphs. (See also Leavell and Clark [12].) Some preventive health care measures are directed toward individuals, often identifiable as being at higher than normal risk. Other measures are directed toward all members of the community, independent of individual risk assessments; these are the environmental measures. Within the former category, it is useful to distinguish betwcen primary and secondary prevention. Primary prevention refers to activities intended to prevent a disease from developing by reducing the prevalence of a hcalth hazard. Examples are immunizations. brushing and flossing teeth and gums, and the avoidance of smoking. Secondary prevention refers to attempts to identify discases before they are symptomatic to catch them at an early stage in which they can be cured or their untoward effects minimized. Examples are Pap smears and screening for high blood pressure. followed by treatment where indicated.

Prcventive health measures vary along a spectrum of relative involvement or level of participation (activity) required of the recipient of the prevention. Environmental measures are necessarily passive: that is, the individual receives the benefits of the measure through no (or minimal) effort of his or her own. For example, all milk drinkers consume vitamin D; salt users consume iodine; air pollution abatement pro- 
vides all citizens with clean air. Within the class of personal health measures, the individual's role varies from reasonably passive to very active. Receiving an immunization requires only that the individual present him- or herself to a provider. By contrast. quitting smoking requires considerable initiative by the individual. In the former (less active) case. something is done to the individual; in the latter (more active) case, the individual does something. A further element in the spectrum concerns repetition: those measures which require that the individual repeat the measure frequently generally involve a greater degree of activity. That is where, for example, the issue of compliance arises in the drug treatment of hypertension. Other things being equal. one might assume that the less initiative or active, sustained participation required of the individual recipient, the more successful the preventive measure would be.

The final dimension in the schema concerns whether the preventive measure is produced by an individual or by the community. Traditional medical preventive measures-immunizations, topical fluoride treatment of children's teeth, annual physical examsare delivered to individual consumers by individual medical professionals. Nonmedical professionals can also deliver individual preventive services; for example, counseling by social workers. At the other end of the spectrum are community-produced preventive measures. Most environmental activities fall into this category. Particularly given the growth and the importance of television. personal preventive measures are increasingly reaching high risk individuals from community sources. A prominent example of this was the anti-smoking campaign on TV and radio from 1968 through 1970 .

This classification schema omits tertiary prevention, the treatment of, or rehabilitation following, a disease which was detected after appearance of a sign or symptom. Such treatment or rehabilitation is preventive in that its intent is to minimize the debilitating effects of an existing illness; that is. to prevent further undesirable consequences. In this spirit, all of medicine is prevention oriented. I have chosen to limit this paper's focus to what I believe the word prevention most commonly connotes: avoidance or minimization of undesirable consequences of presymptomatic disease.

\section{THE COST CONSEQUeNCES OF PREVENTIVE ACTIVITIES: EMPIRICAL EVIDENCE AND POLICY IMPLICATIONS}

The state of the art in evaluating the cost-containment potential of prevention measures is fairly rudimentary in terms of both methodology and empirical understanding. The methodology involves assessing the relationships between specific preventive activities and health outcomes (i.e. the production function) and valuing costs of the former and benefits of the latter. The assessment process suffers from the long lead time between activity and results, the inevitable presence of confounding variables, and the relative paucity of studies undertaken to date. Given the limitations. one should read the better studies in the literature as providing only reasonable approximations of the relevant benefits and costs.
The presentation here will follow the classification schema in Figure 1. First I will consider personal preventive measures delivered by individuals. then personal measures provided by the community. and finally environmental measures.

\section{Personal preventive measures delicered hy indiciduals}

The traditional concept of prevention in the medical field is primary preventive care delivered by medical practitioners to individual patients. One category of such care--immunizations against certain communicable diseases--is generally accepted as one of medical science's greatest contributions to human welfare. The evidence of the effectiveness. the low cost. and the direct and indirect economic benefits of such immunizations makes the social value and the costcontainment implications of most of the standard immunizations beyond question. Representative studies suggest that immunization programs often pay for themselves many times over. For example. Albritton [13] estimated that from 1966 through 1974. the U.S. measles immunization program produced benefits in excess of $\$ 1$ billion, or more than $\$ 10$ for every dollar in program cost. (See also Witte and Axnick [14].) The success of many such immunization programs, however, does not imply that immunization per se is a worthwhile activity. For example there is a debate about the relative costs and benefits of mumps vaccine.

The rationale for nonmarket (i.e. government) involvement in the provision of immunizations is that the benefits of an immunization-or the costs of a communicable disease-are not borne exclusively by the individual who chooses to receive or to forego an immunization. In the former case. one individual's receipt of an immunization affords protection from the disease not only for that individual. but also for others with whom the individual comes in contact. Similarly, the individual's failure to be immunized places others at increased risk of acquiring the disease, should the individual contract it. This "negative externality" of communicable disease (and hence "positive externality" of immunization) has combined with the consensus on the desirability of most common immunizations to remove from the policy arena the issue of whether or not such immunizations should be provided to all, regardless of ability or willingness to pay. The issue now is how to encourage individuals to get these immunizations. The absence of recent major outbreaks of polio. for example. seems to have led many people to assume that there is no need to have their children protected against this disease. The dangers inherent in such neglect have been emphasized by the National Immunization Work Groups [15]. Some states and localities have mounted effective campaigns to get school-aged children immunized. The apparent success of such programs might suggest their serving as models for other communities.

Another category of provider-delivered primary preventive care is less clearly cost-effective and seems to be less frequently (or less conscientiously) practiced: patient education and counseling concerning health behavior. The evidence is overwhelming that individual behaviors account for substantial portions of the costs of illness. Smoking is responsible for $20^{\circ}$, 
of all neoplasms (including $90^{\circ}$ of lung cancers), $25^{\circ}$ \% of diseases of the circulatory system, and $40^{\circ}{ }_{\text {of }}$ of respiratory system illness. In dollar terms, smokinginduced illness costs American society $\$ 35$ billion annually, with direct medical costs exceeding $\$ 10$ billion $[9,16,17]$. The costs of alcohol abuse have been estimated to be in excess of $\$ 50$ billion, including roughly $\$ 15$ billion in direct medical costs $[9,16]$.*

Despite such figures. many medical practitioners devote little effort to counseling their patients on health behavior unless the patient presents with a behavior-related disease or symptoms. In part this reflects the physican's sense of frustration: many physicians believe that their counseling efforts go for naught [18]. In part, it reflects the physician's lack of education on how to counsel. Yet surveys and studies repeatedly report that both the advice of physicans and their behavior are significant influences on the health behavior of the public. In short, it is unclear whether a campaign should be mounted to encourage physicians (and other medical professionals) to counsel their patients on health-promoting behaviors. One would have to assess the costs of such an effort plus the opportunity costs of providers' time devoted to counseling and compare these costs with long-run changes in patients' behavior and the resulting reductions in illness and its associated costs. More health behavior counseling by medical professionals might have significant returns but the price tag would also certainly be considerable.

Personal health care measures oriented toward secondary prevention include screening and early treatment of disease. The cost-effectiveness of such measures appears to vary widely from one activity to another. A generally favorable consensus has arisen concerning screening and early treatment for high blood pressure [19-22]. uterine-cervix cancer [10], and a few other cases. In each of these, screening and early treatment may well pay for themselves in terms of direct medical savings: they are clearly cost-beneficial when indirect cost savings are included. The case for hypertension screening and treatment is sufficiently obvious to many businesses and unions that screening has become routinized in many workplaces. Economically motivated screening would appear to be as strong an indication of the cost-saving potential of preventive measures as can be found. Conversely, the indifference of business toward many prevention activities suggests either that cause-and-effect healthpromotion relationships are not obvious. programs are perceived to be ineffective. or benefits are deferred beyond the point of financial interest to the companies (e.g. into retirement). If lack of knowledge is the problem. experiments and benefit-cost analyses may play a role in the future proliferation or limitation of workplace prevention programs.

Certain screening procedures are of questionable value. The annual physical examination, long a cornerstone of preventive medicine, has recently been attacked as costly and having a low yield of asymptomatic disease conditions which medicine can remedy [23]. Physicals can run from $\$ 30$ to $\$ 500$. depending

* Throughout this paper, dollar figures represent estimates from the literature inflated approximately to current doliars. mainly upon the number of diagnostic tests. While the low end of the range might be rational, including blood pressure checks. Pap smears and the like. the upper end suggests the theoretical possibility that as a nation we could spend over $\$ 100$ billion a year on physicals alone, assuming physicans threw their entire diagnostic armamentarium at every man. woman. and child. To justify even a significant fraction of that total. the yield would have to be much higher than it is currently understood to be. The same might be said about individual tests which are standard components of physicals. For example. EKGs, which are not costly on a per-test basis, are expensive in the aggregate due to the frequency of their administration. though their usefulness on a mass screening basis is unestablished [23]. It should be emphasized that the attack on the conventional annual physical exam need not be interpreted as an attack on all periodic health appraisal. Periodic-not necessarily annualappraisals, with screening and counseling tailored to the individual's age and sex. may prove both effective and relatively inexpensive [24-26].

The cost containment potential of specific screening procedures remains open to question. Screening for colo-rectal cancer has become a routinized part of physicals, particularly for middle-aged and older adults. Sigmoidoscopy adds unpleasantness to a test which seems to have a low yield among asymptomatic patients [23], yet many physicians strongly recommend the test for patients over 40 years of age. One writer has commented favorably, from a cost-containment perspective, on the annual administration of a stool guaiac test for all adults over the age of 55 [9]. However. as occurs all too frequently, this author appears to equate detection with treatment, ignoring the costs of the latter in calculating net benefits. Another study of the costs and benefits of the stool guaiac found that while a single test is reasonably inexpensive, the marginal cost of cancer detection rises to an incredible $\$ 47$ million for the sixth test [27]

Universal periodic mammographic screening of adult women for breast cancer has recently been challenged as producing more cancer than it finds and contributes to curing $[28,29]$. Most of the experts favor continuing mammographic screening of women over the age of 55 and discontinuing the procedure in asymptomatic women under 35: there is less consensus as to the group inbetween 35 and 55 . Having long been a "cause" of the American Cancer Society, routine mammography continues in many medical practices. To contain medical costs, and protect health. governments and voluntary agencies might assess the extensiveness and location of use of this procedure and then try to get practice to conform to the newly-accepted standards.

PKU screening among newborns is required by law in several states. Like many others, the procedure is cheap per test but expensive in the aggregate due to its mandated frequency. An analysis of Massachusetts program of newborn screening for metabolic disorders found PKU screening highly cost-beneficial. principally due to its ability to avoid later institutionalization [30]. An analysis of Mississippi's screening program produced similarly favorable conclusions [31] 
Screening for kidney disease appears to hold the potential of significantly reducing the incidence of end-stage renal disease and thereby reducing the high cost associated with renal dialysis and kidney transplantation. An HEW-sponsored study determined that screening, especially of high-risk populations, was economically a vastly superior strategy to maintaining patients who have reached end-stage disease [32]. (For a contrasting view, see Frame and Carlson [24].) The authors of the HEW study estimated that the benefits of screening exceeded costs by a factor of anywhere from 7.5 to 130 times, depending on the population screened and the method of screening. By contrast, the costs of dialysis were estimated to exceed the benefits, while the costs and benefits of transplants were rated at about equal. Despite such suggestive findings, Federal policy today clearly supports maintenance over screening.

As the HEW-sponsored study emphasizes, the value of screening programs is a function of the population screened. Programs oriented toward high-risk groups can be expected to have a higher relative yield of positives than programs directed at an entire population, but identifying high-risk individuals and securing their participation in a screening activity may be difficult and costly. Similarly, the periodicity of screening affects both the yield (hence potential benefits) and costs of screening. The cost-effectiveness of screening programs is invariably a function of such factors. Their implications warrant considerable programspecific exploration.

As with most preventive measures, the temporal relationship between the costs and benefits of screening works as a disincentive for individual businesses, communities, and even states to sponsor screening programs. The nature of most screening activities is that costs are incurred today, while benefits are deferred into the future. Given migration-from one job to another, to another community, to another state - the sponsor of a screening program is less likely to reap the benefits of the program (a) the later benefits are realized and (b) the "smaller" that sponsor"s "territory". This suggests that the natural locus of many prevention activities is that which is least likely to suffer from out-migration. In the instance of a country, that will often be the central (federal) government, though the ability to capture benefits must be weighed against possible diseconomies of scale in program operation.

In summary, selective advocacy of screening procedures seems a rational approach to allocating scarce prevention resources. Some procedures-e.g. high blood pressure screening and treatmentpromise considerable returns in terms of both direct medical savings and avoidance of indirect productivity losses. Other procedures, including elaborate

* A problem in extrapolating from the literature is that studies are often based on programs administered under conditions favorable to the desired output. Thus, a specific screening program may have to deal with a population which is more remote or intransigent than that of a study. In such a case. it is unreasonable to directly employ the study's estimates of per-case cost and benefit. Doing so is a common source of error in attempting to estimate the costs and benefits of nationwide prevention programs [9]. annual physicals. may be destined to consume more resources than they can save. The issue of the relative costs and benefits of screening remains unresolved for a large number of diseases and under a variety of circumstances. Further study is called for, with the caveat that findings inevitably will have to be adapted to the specifics of each situation.*

Personal preventive measures delivered by the community

The possibility of preventive efforts oriented toward high-risk individuals but provided in a collective or community fashion reflects in part the growth and pervasive influence of television. The idea of using this medium is not new-for years. commercial interests have used it to sell carpet. cars. and candy-but its application in health promotion has been limited [33]. As a consequence, many health professionals would overlook this category in identifying types of prevention activities.

In part. the lack of use of TV and other media reflects the high unit cost of commercial time and the limited resources available to both governmental and voluntary agencies interested in these issues. However. the ability of TV to reach and apparently influence large numbers of people represents an opportunity deserving serious exploration. For example, the "equal-time" anti-smoking messages on TV and radio from 1968 through 1970 appear to have had a significant impact on getting people to reduce or quit smoking [34.35]. Until the middle of the decade of the 1970s, those years represented the only period since the Great Depression in which U.S. per capita cigarette consumption declined for more than two successive years. Furthermore, consumption increased the first year after the equal-time messages were removed from TV. While it is impossible to assess precisely what would have resulted had the concentration of messages continued on TV. there is sound reason to believe that smoking rates would have decreased even more. or at least not have risen again as rapidly as they did $[34,35]$.

The smoking decreases induced by the broadcast anti-smoking messages were not large -2 to 6 percent of total cigarette consumption per year [36]-but a comparison of the effective cost of the messages $(1970$ donated air time worth roughly $\$ 130$ million in current dollars) with the economic burden imposed by smoking (some $\$ 35$ billion per year) suggests that the messages need not have reduced smoking by much in order to represent a cost-effective prevention activity. The case for media-based health education efforts is strengthened by recognizing the potential of utilizing Madison Avenue expertise in the design and marketing of health behavior advertising [37]. In addition to smoking, greater efforts might be directed toward other health behavior problems including alcoholism. the nation's most socially costly behavioral problem.

Community-based economic incentives can be used to attack behavior-induced illness. In the case of smoking, there is a low-cost method to simultaneously reallocate the associated costs in a more equitable fashion and possibly reduce the extent of the habit. Insurers could be urged for conceivably required) to offer preferential premiums to nonsmokers. Smokers are responsible for higher pre- 
miums (and taxes) for medical. life. home-owners. and car insurance: approximately $7^{\circ}{ }_{\circ}$ of direct medical costs are associated with cigarette smoking: the lower life expectancy of smokers results in higher life insurance premiums: over $\$ 200$ million of annual fire losses are due to smoking and drinking: and smokers have higher rates of automobile accidents $[16,17]$.

Higher insurance premiums for smokers would place the economic burden of this habit on those who engage in it. If the annual insurable costs of smoking total $\$ 300$ per smoker and approximately a third of all adults are smokers, each adult American is paying roughly $\$ 100$ per year in unnecessary taxes and insurance premiums. With this burden reallocated to smokers alone. they would have an additional incentive to discontinue smoking and nonsmokers would not be (unfairly) saddled with a portion of the economic burden of smoking.* The same logic could be applied to alcohol abuse, though with the social costs per alcoholic exceeding $\$ 5.000$, and with alcoholism considered by many to be a serious illness. society might rationally choose to treat alcoholism differently from smoking.

\section{Entironmental health measures delivered by the commu-} nity

This is the traditional and fundamental public health category, representing in the classification schema both the largest number of prevention activities of major significance and the generally most costeffective measures. It does not follow logically, however. that this is necessarily the most fruitful area for society's attention. because many of the clearly costbeneficial activities have already been undertaken. Milk is enriched with vitamin D: most communities' water supplies are fluoridated: cities have sanitation services and facilities. All such activities serve passive, primary prevention functions in large groups of the population. with beneficial consequences which today seem beyond question.

The socially provided prevention measure which has received most attention nationally in recent years is pollution control. Governmental action has been substantial in the areas of both air and water, and pollution discharge by automobiles and industrial plants. A recent study suggests that industrial pollution control is probably worth the investment, with smokestack regulations yielding net benefits estimated to total $\$ 9.5$ billion in 1979 . but controls on automobile cxhaust appear to be excessive. with social costs predicted to exceed social benefits in 1985 by $\$ 8.7$ billion [38].

The "growth" fields in the community/environmental category involve control of toxic substances and

* The basic hindrance to preferential premiums for nonsmokers is the difficulty of determining whether or not someone is or recently has been a smoker. The development of an inexpensive and reliable laboratory test might solve this problem. Once one becomes commercially available. government might use its powers of persuasion, or its legislative authority, to expedite insurers offering differential premiums.

+ For a flavor of the debate on the costs and benefits of automobile safety regulation. see Peltzman [42] and General Accounting Otfice [43]. occupational hazards. The Office of Toxic Substances is joining other federal agencies to grapple with the extraordinarily complex technical and social issues involved. NIOSH (National Institute of Occupational Safety and Health) and OSHA (Occupational Safety and Health Administration) continue their efforts to learn about and reduce occupational hazards. These areas seem to be of great importance in terms of both their medical and productivity cost implications. For example, some scientists attribute as much as $80^{\circ}{ }_{\circ}$ of cancer to environmental causes. many of which are concentrated in and around manufacturing workplaces. Accidents are also responsible for substantial productivity loss, as well as medical and disability payments. Desite the burgeoning evidence on such hazards, relatively little analysis of costs and benefits has been undertaken. This is an area where an investment in knowledge may have a high prevention payoff. Utilizing new and existing knowledge, government could promulgate and enforce laws designed to reduce hazards with significant social cost implications. In contemplating such laws. however, attention must be paid to the significant social costs of greater regulation of industry-costs in terms of production. employment and like [39].

Another community/environmental area possibly deserving greater attention than it now receives is highway safety. With tens of thousands of people killed and many more injured on highways each year. the human and economic consequences of automobile accidents are staggering. Technological improvements in cars or highways, or simply stricter enforcement of speed limits. deserves serious consideration by policy makers $[40,41]$. Pecuniary incentives might be encouraged, for example, to reduce the teenage accident rate. This might be achieved by urging the major automobile insurers to refine their rate structures to reduce the premiums of teenagers and young adults for each year their driving records remain clean. $t$

Basic bioscience research is an area which. though difficult to evaluate, seems to have had a significant payoff $[44,45]$, yet real funding for such research has decreased significantly in recent years. Sponsorship of bio-medical research properly belongs at the national level: the benefits of productive research generally become part of the public domain, reflecting both ethical considerations and the practical difficulty of keeping basic research findings secret. The short-term prospects for increasing this prevention activity do not appear favorable: the exigencies of budget-cutting. the intangible nature of the benefits of basic bioscience research. and the lack of a vocal constituency augur stagnation or continuation of declining resources.

\section{CONCLLSION}

The preceding cursory review of the evidence suggests that there are selected. significant opportunities in prevention to reduce the costs of illness. both direct and indirect, pecuniary and nonpecuniary. The problem is to identify and understand those opportunities, to determine how to exploit them effectively. to mobilize the requisite resources. and to mount a successful effort. 
The very existence of promising opportunities is directly indicative of the difficulty of carrying the above process from start to finish. Were the process not so complex. the opportunities likely already would have been identified and exploited. The difficulties include the following:

-The empirical evidence on individual prevention activities is rarely precise or definitive. In large part, this is a function of the lag between a preventive measure and its ultimate health consequences. Given all the intervening and confounding variables, establishing an absolutely certain relationship is difficult. As a result, skeptics or groups whose interests might be damaged by an established cause-and-effect relationship can argue about the validity or reliability of a tentative finding. Furthermore, some neutral decision makers may be reluctant to act on findings they perceive to be uncertain.

-Even when a convincing cause-and-effect relationship has been established, the economic benefits of prevention are diffuse, somewhat abstract, and, perhaps most importantly, deferred.

- The diffuseness of benefits refers to the fact that while benefits may be certain and substantial for an entire community, their ultimate distribution across individuals is unclear. Hence the benefits are less meaningful to individuals, and there is no favorable vocal interest compared to that which would exist if the distribution of future benefits were known.

- The abstractness of the benefits results from their taking the form of distant, nonoccurring medical costs and, in the case of productivity losses averted, future increased incomes and hence tax payments. Such benefits are less easy to see than the immediate budgetary expenditures required by prevention programs. In an era of cost-consciousness, this vision problem is particularly acute for the legislator confronting a re-election battle.

-The legislator's myopia also results in a heavy discounting of phenomena occurring in the future. Politicians tend to live in a sequence of "short runs." from one election to the next; the "long run" has relatively little meaning. Thus the fact that benefits are deferred is a strike against political support for prevention activities.

- Preventive measures are generally quite discretionary. Especially in times of fiscal restraint. in the absence of a very powerful and vocal interest group it is difficult to get legislatures to vote additional expenditures. The federal budgetary process, as well as that of many states, sets prevention programs in competition against facilities construction programs, programs funding illness care, and so on. While ideally, government should support all programs whose social benefits exceed their social costs, in practice the different programs are vying for shares of a relatively fixed pie. As the less discretionary shares of that pie grow (e.g. Medicare), the more discretionary programs are at jeopardy of shrinking.

Another argument leveled against prevention measures is that when one problem is prevented another will arise in its place. Especially if prevention in general is very successful, a result would be growth in the elderly population which consumes considerably more medical care than the working-age popula- tion. Consequently. rather than reducing direct expenditures on medical care. prevention might simply postpone and possibly increase expenditures.

The fallacy in this line of thinking is that it ignores the time element. Other things being equal. postponing costs is economically desirable. This relates to the discounting concept introduced earlier. Even controlling for inflation. a dollar today is worth more than a dollar next year. Perhaps the easiest way to see this is to take a numerical example. Suppose that a preventive measure prevents a current fatal illness that would have required medical treatment costing $\$ \geq 000$. Instead. the person whose life was saved develops a different and expensive fatal condition 40 years later which requires $\$ 10.000$ of medical care (again. controlling for inflation). Without discounting. the preventive measure appears to result in dramatically increased medical expenditures. However, suppose that the individual (or society. or the medical system) had taken the $\$ 2000$ saved and had denosited it in a savings account at six percent interest. At the end of the 40 years. that account would be worth $\$ 20.571 .40$-enough to cover the "greater" medical expense with plenty to spare. Such a simplistic analysis ignores the productivity gains resulting from the prevention and, of course. the non-pecuniary or "inherent" value of saving a life. But it emphasizes that postponing costs is also a means of containing costs.

The review in the preceding section identified different categories of preventive measures. The distinctions seemed useful for expository purposes. but in addition they can be useful from a policy perspective. The distinctions identified dimensions, or variables, which appear likely to affect the probability and extent of a policy's success. Combined with consideration of current emphases in prevention, this categorical analysis can help to identify classes of preventive measures which seem most likely to yield a significant cost-containment payoff.

An example of a relevant variable is the relative activity required of the recipient of a preventive measure; that is, the degree to which prevention's success is dependent on the initiative of the individual. Especially when such initiative ("action", "compliance") must be repeated frequently, a program is less likely to achieve a high rate of success than where the individual passively receives a preventive measure. Compare, for example, quitting smoking and receipt of an immunization.

A second variable is whether the preventive activity has a primary or secondary prevention orientation. i.e. whether it attempts to prevent the onset of the disease problem or to identify and limit the consequences of an early disease problem. While most public health workers would identify primary prevention as the more cost-effective activity, more data are needed to firmly establish this generalization. and case-by-case assessments might prove necessary. Surely it is cheaper to prevent dental caries by fluoridating a community's water supply than by screening and treating caries [46]. However, while preventing respiratory diseases associated with air pollution seems preferable to finding and treating such illnesses, economically speaking society can go too far in its attempts to do the former [38]. 
A third variable is the "publicness" of the delivery of a preventive activity. With rare exceptions, it is clear that an individually- (especially physician-) provided preventive measure is more expensive than a public good directed toward the same population. The element of the benefit-cost calculus which is necessary to favor the former delivery strategy is much greater effectiveness (i.e. benefit), which may be a function of the technical qualities of the activity or the receptivity (e.g. compliance) of the recipients of the measure. In general. the most cost-effective public health measures have been those characterized by a high degree of "publicness" in their delivery (for example, fluoridation and sanitation).

A final variable is the "publicness" of the recipient of a preventive measure. Identifying and reaching a high-risk or susceptible population can itself be an expensive undertaking. Preventive measures directed toward an entire community have the advantage of avoiding this expense. Thus, counseling people not to smoke is less expensive on a per-smoker basis through use of the broadcast media than through individual consultations between smokers and their physicians. Again. however. cost is only one side of the equation. One must always weigh outcome. which may well be greater in the individualized receipt of advice [47]

Several of these category-defining variables have played significant though often implicit roles in determining where communities would invest their prevention dollars. To focus on currently economically promising areas of preventive activity, one can identify theoretically appealing categories and compare these with categories in which prevention activities have been concentrated. Categories appearing theoretically attractive which have not been heavily exploited would appear to be those most worthy of current attention.

Both empirical evidence and simple logic recommend the "first" and "last" cells of the prevention schema (Figure 1$)$ as the most cost-beneficial categories. The first cell respresents primary, less active measures delivered by individuals to individuals. The last cell contains (primary and passive) environmental health measures produced by the community for all of its members. Many of the opportunities in these categories have already been partially or largely exploited. By contrast. certain conceptually less attractive types of preventive activity may hold considerable potential for realizing health benefits and long-run cost savings. A prime example is the use of the broadcast media, especially television. to promote desired heath behaviors. On the surface this approach violates a couple of the "rules" of effective prevention activity: it represents impersonal delivery of advice (or persuasion) and to be effective. it requires repeated "activation" of the recipient of the advice (e.g. a smoker must actively choose not to smoke several times a day for weeks or months). Despite these "rule violations," the potential in this approach derives from (1) the mass exposure it achieves. (2) the apparently significant influence of TV on American attitudes and hehavior (3) the limited use of the approach, and (4) the fact that to be cost-effective. the approach requires only a small rate of response: that is. a small percentage of smokers reducing or quitting smoking can have a substantial impact on health and health costs in terms of absolute magnitude. Madison Avenue has used this approach with great success for a couple of decades now. and practitioners of the TV advertising art have suggested that it could be extended to the realm of health behavior [37]

Concentration on health behavior and environmental and occupational hazards is particularly recommended by recognition that these represent the predominant continuing sources of preventable iliness and mortality. In large part. the prevalence of behavior and environment-related chronic diseases reflects the success of past prevention efforts. Just as curative medicine must turn its attention from the infectious acute diseases to chronic individual conditions. public health must turn its preventive focus from biologically communicable diseases to socially transmitted (but individually-based) problems (e.g. smoking).

With respect to any of the health problems society might choose to attack, there is an array of policy options which warrant consideration. The cheapest and least "offensive" of these (because it is least coercive) is "moral suasion", public figures using their moral authority to persuade citizens, physicians, industry, insurers or others to alter certain behavior. Though inexpensive, such "jawboning" generally seems to have limited effectiveness. Secondly, government can provide explicit pecuniary incentives and disincentives to encourage specific behaviors. Increased excise taxes on tobacco and alcohol would discourage some consumption: a graduated tax on cigarette tar and nicotine content would encourage some smokers to switch to lower tar and nicotine cigarettes [48.49]. Physicans can be offered bonuses for performing specified preventive activities. businesses can be permitted tax credits for screening programs, and the struggling health maintenance organization movement can receive additional governmental financial support $[50,51]$.

The third strategy is the legal one. Through both development of new legislation and enforcement of existing laws, governments at all levels can mandate reductions in the amount and extent of health hazards. While the temptation may be to contemplate new laws, it would seen productive to consider encouraging enforcement of existing statutes. Speed limits can be more strictly enforced, as can school entry childhood immunization requirements.

Finally, the various levels of government can provide direct services. Worthy of note are local health departments, which offer an institutional base for the promulgation and delivery of services. Originally in the vanguard of creative public health. local health departments have decreased their innovative thrust in recent decades, and many have been relegated principally to providing care for the medically indigent. The fact that such departments are organizationally and structurally in place suggests that they might serve as a cost-effective vehicle for change.

In closing. I wish to emphasize the importance of the context in which one asks whether or not. and where. opportunities lie for cost containment through prevention. The tenor of the present cost-containment debate has a medical monetary ring to it, and a shortterm one at that. Concern focuses on decreasing the rate of growth in expenditures on health care in the 
immediate future. Indeed. in most policy circles the focus is narrower still, concentrating exclusively on defined medical care institutions (e.g. hospitals and nursing homesl. Viewed in this light. many prevention measures hold little promise for serving the cost-containment objective. As noted at the outset. prevention often involves immediate dollar outlays and deferred benefits; as such, it is the antithesis of short-rim cost control. Furthermore, the benefits of prevention are not exclusively pecuniary: even within the pecuniary class, benefits are often subtle and indirect, though still very real. A decreased welfare burden due to lessened disability may be difficult for a legislator to perceive or, if perceived to sell to constituents. Increased tax receipts due to increased productivity suffer a similar fate when government's health cost accountants balance their ledgers. In the current atmosphere. even understanding of such real pecuniary benefits may be inadequate to influence health cost containment policy. Prevention is a device to contain social costs: health cost containment may be an effort to control a specific subset of line items in the government budget.

The above does not mean that all prevention measures are ruled out by a short-term, pecuniary. institutional focus. Rather, the class of applicable preventive activities is limited to those with a relatively rapid medical cost return. However. I have chosen throughout this paper to present the examination of prevention in what I believe to be its appropriate broader social context. In that context, a wide variety of prevention measures. new and old, appear to hold considerable potential for enriching the nation over the long run through a healthier, more productive citizenry, through greater tax revenues and lesser expenditure demands. and through decreased health care expenditures.*

The potential of prevention is known or conjectured. depending on the specific measure under consideration. A striking feature of the prevention literature is the paucity of solid empirical understanding. A principal conclusion from this review is that selected applied research. directed toward identifiable problems. would seem a worthwhile precursor to an economically significant prevention initiative.

\section{RFFERENCES}

1. Cooper B. and Rice D. Economic cost of illness revisited. Soc. St't. Bull. 39, 21, 1976.

2. Klarman H., Francis J. and Rosenthal G. Cost-effectiveness analysis applied to the treatment of chronic renal disease. Mod. Core 6, 48. 1968.

3. Acton J. Measuring the Social Impact of Heart and Circulatory Discase Programs: Preliminary Framework and Estimates. Rand R-1697-NHLI, 1975.

4. Haveman R The Economics of the Public Soctor. Ind edn. Wiley. Santa Barbara, 1976.

* Implicit in any consideration of the spectrum of prevention activities is a possibility which has not been discussed explicitly due to this paper's concern with cost containment: namely, a preventive measure might lead to increased expenditures yet be deened desirable due to the social. perhaps nonpecuniary benefits it confers. Thus the set of socially desirable prevention measures may well be considerably larger than the set of cost-containing meatsures.
5. Merewitz L. and Sosnick S. The Budu'ts Ne't Clothe's-A Criticue of Plaming-Prodramming-Badecting and Benefit-Cost Analisis. Markham. Chicago. 1971.

6. Baumol W. On the discount rate for public projects. In Public Expendinare and Policy Analisis tEdited br Haveman R. and Margolis J.1. p. 161. Rand MeXally Chicago. 1977.

7. Dunlop D. Benefit-cost analysis, a review of its applicability in policy analysis for delivering health services. Soc. Sci. Med 9. 133.1975.

8. Klarman H. Application of cost-benetit analysis to the health servies and the special ealse of technology innovation. Int. J. Hlth Sert. 4, 325, 1974.

9. Kristein M. Economic issues in prevention. Pre't. Mad. 6. 252, 1977.

10. Grosse R. Cost-benefit analysis of health service. tim. Am. Acad. pol. soc. Sci. 399.89. 1972.

11. Wcinstcin M. and Stason W. Foundations of cost-effectiveness analysis for health and medical practices. $V$. Engl. J. Med. 296. 716.1977.

12. Leavell $H$. and Clark E. Levels of application of preventive medicine. In Pre'tentite . Medicine for the Dector and His Community. Chap. 2. McGraw-Hill. New York, 1965.

13. Albritton R. Cost-benefits of measles eradication: effects of a federal intervention. Policy Anal. 4. 1. 1978.

14. Witte $J$. and Axnick $N$. The benefits from 10 years of measles immunization in the Lnited States. Puhl. H/th Rep. 90, 205. 1975

15. National Immunization Work Groups. Reports and Recommendations. Submitted to the Assistant Secretary for Health. DHEW. March 15, 1977

16. Luce B. and Schweitzer S. Smoking and alcohol abuse: a comparison of their economic consequences. . V. Ehal. J. Med. 298. 569, 1978.

17. Califano J. Address to the National Interagency Council on Smoking and Health. January 11. 1978.

18. Breitman $\mathrm{G}$. Preventive medicine--a myth'? $W_{\text {. }} J$. Med. 125. 236, 1976.

19. Weinstein M. and Stason W. Hipertension. A Policy Perspectite. Harvard Univ. Press, Cambridge, 1976.

20. Freis E. et al. Veterans Administration cooperative study group on antihyptertensive agents: effects of treatment on morbidity in hypertension. I. Results in patients with diastolic blood pressures averaging 115 through $129 \mathrm{~mm} \mathrm{Hg.} \mathrm{J.A.M.4.} \mathrm{202.} 1028,1967$.

21. Freis E. et ul. Veterans Administration cooperative study group on antihypertensive agents: effects of treatment on morbidity in hypertension. I. Results in patients with diastolic blood pressures averaging 90 through $114 \mathrm{~mm} \mathrm{Hg.} \mathrm{J.A.M.A.} \mathrm{213.} \mathrm{1143,} 1970$.

22. Bryers F. and Hawthorne V. Screening for mild hypertension: costs and benefits. J. Epid. commun. Hlti 32. 171. 1978.

23. Spark $R$. The case against regular physicals. N.Y. Times Magazine, July 25, 1976.

24. Frame $P$. and Cartson $S$. A critical revicw of periodic health screening using specific screening criteria. $J$. Fam. Pract. 2. 29. 123.189. 283. 1975.

25. Breslow L. and Somers A. The lifetime health-monitoring program a practical approach to preventive medicine. N. Engl. J. Med. 296,601, 1977.

26. Collen M. et al. Multiphasic checkup evaluation study Pretent. Med. 2, 236, 1973.

27. Neuhauser D. and Lewicki A. What do we gain from the sixth stool guaiac? $N$. Enyl. J. Med. 293, 226. 1975.

28. Bailar J. Screening for early breast cancer: pros and cons. Cancer 39, 2783.1976.

29. Seidman H. Screening for breast cancer in younger women: life expectancy gains and losses. An analysis 
according to risk indication groups. Cancer 27, 66 , 1977.

30. Van Pelt A and Levy $\mathbf{H}$. Cost-benefit analysis of newborn screening for metabolic disorders. N. Engl. $J$. Med. 291, 1414, 1974.

31. Steiner $\mathbf{K}$. and Smith $\mathbf{H}$. Applications of cost-benefit analysis to a $\mathrm{PKU}$ screening program. Inquiry 10, 34. 1973.

32. LeSourd D., Fogel M. and Johnston D. Benefit/Cost Analysis of Kidney Disease Programs. U.S. DHEW. PHS Pub. No. 1941, 1968.

33. Farquhar J. et al. The Stanford Three-Community Study: A Community-Based Cardiovascular Risk Education Campaign. Stanford Heart Disease Prevention Program. Stanford Univ.. 1976.

34. Hamilton J. The demand for cigarettes: advertising. the health scare, and the cigarette advertising ban. Ret. Econ. Stat. 54, 401. 1972.

35. Warner $\mathbf{K}$. Clearing the airwaves: the cigarette ad ban revisited. Policy Anal. 5, 1979, in press.

36. Warner $\mathrm{K}$. The effects of anti-smoking policies on the demand for cigarettes in the United States. Presented at 4th World Conference on Smoking and Health. Stockholm. June 21. 1979.

37. Green P. The mass media anti-smoking campaign around the world. In Proceedings of the Third World Conference on Smoking and Health. Vol. II, p. 245. DHEW Pub. No. (NID) 77-1413. 1977.

38. Lave L. and Seskin E. Air Pollution and Human Health. Resources for the Future, Washington, 1978.

39. Nichols A. and Zeckhauser R. Government comes to the workplace: an assessment of OSHA. Pub. Int. 49. 39. 1977.
40. Little A. D. Inc. Cost-Effectiveness in Traffic Safoty. Praeger. New York. 1968.

41. Fuchs V. Motor accident mortality and compulsory inspection of vehicles. J.A.M.A. 201. 657. 1967.

42. Peltzman S. The effects of automobile safety regulation. J. pol. Econ. 83. 677, 1975.

43. General Accounting Office. Effectiveness, Benefits, and Costs of Federal Safety Standards for Protection of Passenger Car Occupants. Report to the Comm. on Commerce. U.S. Senate, by the Comptroller General, 1976.

44. Chen M., Wagner D. and Landefeld J. Gains in Mortality from Biomedical Research. 1930-1975: An Initial Assessment. Public Service Laboratory. Georgetown Univ.. 1977

45. Weisbrod B. Costs and benefits of medical research: a case study of poliomyelitis. J. pol. Econ. 79. 527. 1971.

46. Davies G. Cost and Benefit of Fluoride' in the Prevention of Dental Caries. World Health Organisation. Geneva. 1974.

47. Koskela K., Puska P. and Pallonen U. A comprehensive television smoking cessation programme in Finland. Presented at 4 th World Conference on Smoking and Health. Stockholm. June 19, 1979.

48. Drayton $W$. The tar and nicotine tax: pursuing public health through tax incentives. Yale Law J. 81, 1487, 1972.

49. Harris J. Taxing tar and nicotine. Am. Econ. Rer.. in press.

50. Starr P. The undelivered health system. Publ. Interest 42. 66.1976.

51. Warner $\mathrm{K}$. Health maintenance insurance: toward an optimal HMO. Policy Sci. 10, 121, 1978-79. 